\title{
REVISTA
}

$\mathrm{DE}$

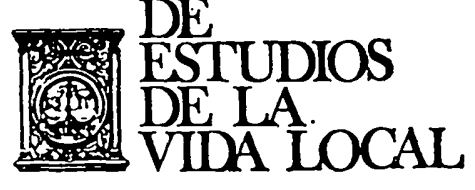

VI. REVISTA DE REVISTAS

13 


\section{DERECHO ADMINISTRATIVO (")}

\section{REGLAMENTOS. 35.077.6.}

Carro fernández, J. L.: La potestad reglamentaria del Gobierno y la Constitución. Madrid, DA, núm. 188, octubrediciembre 1980, págs. 188 a 232.

El propósito del autor ha sido analizar la extensión de la potestad reglamentaria que el artículo 97 de la Constitución del 78 confiere al Gobierno y a los Ministros, así como la necesidad de una ley habilitante para ejercer dicha potestad reglamentaria.

BUROCRACIA. 35.08: 301 .

Crozier, Michel: La crise burocratique (La crisis burocrática). París, REVUE FRANCAISE D'ADMINISTRATION PUBLIQUE, núm. 15, julio-septiembre 1980, págs. 111 a 122.

El autor analiza los diversos aspectos del ambiente de crisis burocrática en que se encuentran las sociedades democráticas industriales y propone una estrategia de cambio basada en la capacidad innovadora de las personas individuales que sufre el rígido ordenancismo.

Curado García, Blas: Comunidad y burocracia. Badajoz, TIERRA EXTREME. NA, núm. 2, 1981, págs. 9-10.

El artículo es una crítica de tipo social y político a la Administración, la burocracia, sus costes y despilfarros, etc.

DELPECH, Lourens: La diffusion des principes du management public dans l'administration américaine: l'exemple du Civil Service Reform Act de 1978 (La difusión de los principios del «management» público en la Administración americana: el ejemplo del Acta de Reforma del Servicio Civil de 1978). París, REVUE FRANCCAISE D'ADMINISTRATION PUBLIQUE, núm. 15, julioseptiembre 1980, págs. 123-138.

(*) Explicación de las abreviaturas:

$\mathrm{CAJ}=\mathrm{El}$ Consultor de los Ayuntamientos y de los Juzgados.

CEUMT = La Revista Municipal, Centre d'Estudis Urbanistics, Municipals i Territorials. Ad. = Administration.

$\mathrm{DA}=$ Documentación Administrativa.

D. Ad. = Droit Administratif.

NR = Nuova Rassegna di Legislazione, Dottrina e Giurisprudenza.

PAR $=$ Public Administration Review .

$\mathrm{RA}=\mathrm{La}$ Revue Administrative.

RAP = Revista de Administración Pública.

RARI = Revista Amministrativa della Republica Italiana.

RDEA = Revista de Derecho Español y Americano.

REP = Revista de Estudios Políticos.

RICA = Revista Internacional de Ciencias Administrativas.

$\mathrm{U}=$ Urbanisme. 
Después de examinar la evolución y la situación actual de la Administración pública americana, el autor analiza la Civil Service Reform Act de 1978, cuyo objetivo es la transformación de aquélla en un organismo eficaz no burocratizado.

\section{FORMACION DE FUNCIONARIOS. 35.088.6.}

VuGHT, Gabriel: La formation permanente et la promotion interne dans le secteur publique (La formación permanente y la producción interna en el sector público). París, Ad., núm. 107, 1980, páginas 28-30.

El artículo trata de la necesidad de formación de los funcionarios públicos para asegurar su movilidad y adaptación, y medidas adoptadas por la Dirección General de la Administración y la Función Pública francesa.

\section{HUELGA DE FUNCIONARIOS.} 35.08: 331.89 .

Cano Mata, Antonio: La huelga de funcionarios. Madrid, RAP, núm. 93, septiembre-diciembre 1980, págs. 129 a 150.

El propósito de este artículo ha sido analizar el artículo de la Constitución Española que regula la huelga de los funcionarios, así como su regulación legal y su efecto, y concretamente la falta de devengo de haberes.

\section{EMPRESAS PUBLICAS. 351.658.115.}

SÁNCHEZ MORÓN, Miguel: Introducción al régimen jurtdico de la empresa pública en España. Madrid, DA, número 188 , octubre-diciembre 1980 , páginas 67 a 128 .

El objetivo del presente trabajo es exponer la configuración jurídica de la empresa pública en España, señalar los orígenes y características fundamentales de su actual regulación, subrayando los problemas más importantes que la misma suscita y apuntar las tendencias actuales $y$ las perspectivas que se abren al legislador español en este campo.
SANIDAD PUBLICA. 351.77.

MÉNDEZ MÉNDEz, Elvira: La descentralización municipal en la acción sanitaria. Barcelona, CEUMT, núms. 29-30, agosto-septiembre 1980, págs. 56-60.

Artículo que, partiendo de la consideración de que actualmente la descentralización de funciones, centros y servicios municipales es necesaria para la participación, pasa a analizar cómo es posible fomentar la participación del ciudadano en la intervención sanitaria municipal.

SEPE: La planification sanitaire dans les rapports entre Etat et Régions en Italie (La planificación sanitaria en las relaciones entre el Estado y las Regiones en Italia). Bruselas, RICA, núm. 3, volumen XLVI, 1980, págs. 233 a 236.

En este artículo se analiza la Ley del 23 de diciembre de 1978, que instituye el servicio nacional sanitario, poniendo de relieve los problemas fundamentales con que se encontró el legislador: costes, interpretación y ámbito de aplicación.

TOulemon, P.: Le projet de loi pour le développement des responsabilités des collectivités locales et ses incidences dans le domaine de l'action sanitaire et sociale (El proyecto de ley para el desarrollo de las responsabilidades de las Corporaciones locales y sus incidencias en el ámbito de la acción sanitaria y social). París, RA, núm. 197, 1980 , páginas 493 a 496.

El artículo analiza el proceso de reforma de las colectividades locales en Francia, especialmente en lo que atañe al campo de la acción sanitaria y de la acción social.

\section{IURISDICCION CONTENCIOSO- ADMINISTRATIVA. 351.9 .}

Milián Massana, Antoni: Extensión de la competencia material de los brganos jurisdiccionales radicados en Cataluña en el orden contencioso-administrativo. Madrid, RDEA, núm. 27, octubre-diciembre 1980, págs. 605 a 612 .

Artículo que pone de manifiesto la necesidad de reformar la actual organización territorial de la jurisdicción contencioso-administrativa. 
Talice, Carlo: Il Tribunale Amministrativo Regionale per il Trentina-Alto Adige (El Tribunal Administrativo Regional para el Trentino-Alto Adigio). Roma, RARI, núm. 131, fasc. núm. 6,1980 , páginas 373 a 375 .

Este artículo pone de manifiesto el sistema normativo de organización de la justicia administrativa en la Región de Trentino-Alto Adigio.

\section{ADMINISTRACION LOCAL}

\section{ADMINISTRACION LOCAL. 352.}

Ghorra-Gobin, Cynthia: Le devenir de la gestion communale (El futuro de la gestión municipal). París, U, núms. 179/ 180,1980 , págs. 48 a 49.

Frente a quienes piensan racionalizar los problemas locales aplicándoles técnicas empresariales, este artículo se pregunta si la gestión de las colectividades locales corresponde ya a dichas técnicas.

Perdigo, Joan: Sobre las últimas medidas en materia de régimen jurídico de las Corporaciones locales. Barcelona, CEUMT, edición catalana, núm. 36, 1981 , págs. 11 a 16.

El artículo está dedicado al análisis del Real Decreto-ley 3/1981 por el que se aprueban determinadas medidas sobre régimen jurídico de las Corporaciones locales (régimen de sesiones y de adopción de acuerdos, contratación, suspensión de acuerdos, funcionarios y régimen jurídicoeconómico).

\section{REFORMA LOCAL. 352.047.}

CotTEn, Michel: Le plan de développement des responsabilités des collectivités locales (El plan de desarrollo de las responsabilidades de las Corporaciones locales). París, Ad., núm. 110, 1980, páginas 39 a 53 .

El artículo analiza el plan de desarrollo de las responsabilidades de las Corporaciones locales anunciado en 1978 en el Senado francés. Se trata de una auténtica reforma que aborda los aspectos prácticos de la gestión municipal y de las relaciones entre las Corporaciones locales y el Estado, con una mayor descentralización.

Gauthier, Yves: La reforme des collectivités locales, projet fondamental (La reforma de las Corporaciones locales, proyecto fundamental). París, Ad., número 110,1980 , pág. 57 .

Breve artículo en el que se ponen de manifiesto los problemas que presentará la reforma de las colectividades locales en curso a partir del proyecto de ley de desarrollo de las responsabilidades locales.

Maragall, Pascual: La reforma administrativa municipal de Barcelona. Barcelona, CEUMT, núm. 34, enero 1981, páginas 5 a 10.

Esta entrevista pone de manifiesto los objetivos generales que se persiguen con la reforma administrativa que se está lle. vando a cabo en Barcelona.

AUTONOMIA MUNICIPAL. 352.072.1.

Rosario PULli, Italo: Il nuovo ordinamento delle antonomia locali (El nuevo ordenamiento de la autonoma local). Firenze, NR, núm. 17, 1979, págs. 1758 a 1764.

Se trata de un estudio en el que el autor expresa su opinión acerca del proyecto de ley de ordenamiento de la autonomía local aprobado por el Senado italiano en noviembre de 1979.

SÁNCHEz MoRÓn, M.: Sobre la autonomia de las Entidades locales: comentarios a la sentencia del Tribunal Constitucional de 2-II-1981. Barcelona, CEUMT, número 37, 1981, págs. 17-19.

El artículo analiza la sentencia del Tribunal Constitucional de 2 de febrero de 1981 en tres aspectos genericamente: las potestades de control de las leyes por el Tribunal, la definición que la sentencia su. pone de la autonomía local garantizada por el artículo 137 de la Constitución y los preceptos derogados. 
HACIENDA LOCAL. 352.72.

CAmps, Enric: La problemática de la $\mathrm{Ha}$ cienda local. Barcelona, CEUMT, número 32, noviembre 1980, pág. 28.

Pone de manifiesto los elementos más importantes del texto de los acuerdos emanados de la reunión de Alcaldes de Valladolid.

LoRzu, Máximo: Comentarios al proyecto del Real Decretoley sobre régimen jurídico, económico y financiero de las Corporaciones locales. Barcelona, CEUMT, núm. 34, 1981, págs. 46 a 48.

Este artículo pone de manifiesto los as. pectos positivos y negativos de este proyecto.

MCCAFFERY, Jerry: Urban finance: dollars, decisions and dilemmas (Finanzas urbanas: dólares, decisiones y dilemas). Washington, PAR, número especial, enero 1981, págs. 105-106.

Introducción a un número especial de la revista sobre el impacto de la escasez de recursos en las finanzas públicas urbanas $\mathrm{y}$ los problemas presupuestarios que la crisis plantea.

\section{ADMINISTRACION PROVINCIAL. 353.}

Garrigós Pico, Eduardo: Precedentes de la división provincial española actual. Barcelona, CEUMT, núm. 38, mayo 1981, págs. 15-18.

Análisis de la realidad provincial española durante el siglo Xvi.

DIPUTACIONES PROVINCIALES. 353.

Cimadevilla, César, y larroque, luis: La función de las Diputaciones provinciales. Barcelona. CEUMT, núm. 38, mayo 1981, págs. 5-13.

Entrevista a los Vicepresidentes de la Diputación de Madrid (Larroque y Cimadevilla) en la que tratan de los problemas actuales y de las perspectivas de evolución del ente provincial.
DALDA, Juan-Luis: Diputaciones provinciales y planeamiento urbanistico: perspectivas. Barcelona, CEUMT, núm. 38, mayo 1981, págs. 37-40.

Artículo sobre la competencia urbanistica de las Diputaciones provinciales.

Marti, Francesc: El futuro de las Diputaciones: el caso de Catalunya. Barcelona, CEUMT, núm. 38, mayo 1981, páginas $19-22$.

Artículo que trata del problema que se plantea en aquellas Comunidades Autónomas "pluriprovinciales» que aspiran a la desaparición de las Diputaciones o a su fusión con el organismo autónomo, en es. pecial el caso de Cataluña.

Martín-Retortillo, Sebastián: En torno a la organización provincial. Madrid, RAP, núm. 93, septiembre-diciembre 1980, págs. 7 a 28.

La intención fundamental de este trabajo, que quiere partir del enjuiciamiento de los presupuestos históricos que se señalan sobre la incompatibilidad de las Diputaciones provinciales con una estructura regional que postulan casi necesariamente soluciones de carácter comarcalizador.

Silva Cienfuegos-Jovellanos, Pedro de: Diputaciones y Comunidades Autónomas uniprovinciales: el caso de Asturias. Barcelona, CEUMT, núm. 38, mayo 1981, páginas 22-24.

Artículo que trata de la polémica sobre la subsistencia o no de l8s Diputaciones en las Comunidades Autónomas uniprovinciales, en especial el caso de Asturias.

Simón Tobalina, Juan-Luis de: $E l$ porvenir de las Provincias. Madrid, CERTAMEN, núm. 451, 1980, págs. 311 y 312.

Estudio de la Provincia como entidad intermedia entre el Estado y el Municipio en el Derecho comparado y en la historia de nuestro Derecho, con una pregunta final acerca del significado del Decreto de la Generalidad catalana, en virtud del cual ésta asume las competencias y funciones de las cuatro Diputaciones catalanas. 


\section{HACIENDA PROVINCIAL. 353.72.}

BORREL, José: Haciendas provinciales: el presupuesto de la Diputación de Madrid, 1981. Barcelona, CEUMT, núm. 38, mayo 1981, págs. $25-31$.

Comentario sobre cuáles son las dificultades a que ha debido hacer frente una Corporación concreta, la Diputación de Madrid, a la hora de confeccionar sus presupuestos para 1981.

\section{ADMINISTRACION REGIONAL}

\section{ADMINISTRACION REGIONAL. 353.}

La Comisión consultiva de la Generalidad de Cataluña. Madrid, CAJ, núm. 5, 1981, págs. 301 y 302.

El propósito de este artículo ha sido definir las competencias, funciones, facultades, organización... del órgano consultivo más importante de la Generalidad: Comisión consultiva.

Ferrero, Afrodisio: Los Delegados del Gobierno en las Comunidades Autonomas. Madrid, CERTAMEN, núm. 452, 1980, págs. 359-362.

Planteamiento de los problemas que suscita esta figura, recogida en el artículo 154 de nuestra Constitución, de sus posibles competencias y de los antecedentes y Derecho comparado.

Lliset Borrell, Francisco: Generalidad potestativa. La organización territorial de Cataluña. Madrid, CAJ, núm. 8, abril 1981, págs. 462-463.

Reflexiones sobre la Generalidad en cuanto a su organización territorial, organización política, etc., distinguiendo la Generalidad-organización frente a la Generalidad-ordenamiento.

Rougevin-Baville, Michel: Régions. Statut particulier de la Région d'lle-de. France (Regiones: Estatuto particular de la Región de lle-de-France). París, D. Ad., núm. 12, 1980, págs. 656-659.

El artículo versa sobre la acción de animación y de control ejercida por el prefecto de la Región de "Ile-de-France» sobre ciertos establecimientos públicos y sociedades de economía mixta.

\section{AUTONOMIA REGIONAL. 353.072.1.}

Bassanini, Franco, y Caretti, Paolo: $A u$ tonomie regionali $e$ poteri comunitari (Autonomía regional y poder comunitario). Milán, LE REGIONI, 1/2, 1980, páginas 84 a 104.

El artículo analiza la relación entre las Regiones y la CEE, tanto en lo relativo a la participación a través de órganos del Estado en la formación de las decisiones comunitarias, como lo relativo a la ejecución directa por ellas del Derecho comunitario.

Bin, Roberto: Il Presidente della Repubblica a la salvaguardia dell'autonomia regionale (El Presidente de la República en la salvaguardia de la autonomía regional). Milán, LE REGIONI, número 4,1980 , págs. 577 a 580 .

Se trata de determinar la posibilidad de actuación del Presidente de la República en orden a la protección de la autonomía regional cuando ésta es violada por una ley de detalle gubernamental.

Fusi Aizpoma, Juan P.: Sobre Navarra. Madrid. CUENTA Y RAZON, número 1, 1981, págs. 75 a 79 .

Este artículo realiza algunas anotaciones sobre la dificil situación actual de $\mathrm{Na}$ varra y sobre las dos posiciones antagonicas y aparentemente irreconciliables en que aquélla se debate.

Garcfa FernÁndrz, Javier: Crónica de la descentralizacion: el panorama descentralizador al acabar 1980 (I). REP, número 17, 1980, págs. 175-202.

Crónica sobre la situación actual en el nivel de las autonomías nacionales y regionales y en el plano del poder local. Presentación de la situación en que se encuentra la descentralización de las Nacionalidades y Regiones. 


\section{ESTUDIOS - JURISPRUDENCIA - CRONICA ADMINISTRATIVA} DOCUMENTOS Y DICTAMENES - BIBLIOGRAFIA

\section{CONSEJO DE REDACCION}

Presidente: D. Luis JORDANA DE POZAS

Manuel Alonso Olea - José María Boquera Oliver - Antonio Carro Martínez - Manuel F. Clavero Arévalo - Rafael Entrena Cuesta - Tomás-Ramón Fernández Rodrúguez Fernando Garrido Falla - Jesús González Pérez - Ramón Martín Mateo - Lorenzo MARTín-Retortillo BAQUER - Sebastián MARtf́n-Retortillo BaQuER - Alejandro Nieto José-Ramón Parada VÁzQuez - Manuel Pérez OlRA - Fernando SAINz de Bujanda - Juan A. Santamaría Pastor - José luis Villar Palasí

Secretario: Eduardo GARCIA DE ENTERRÍA Secretario adjunto: Fernando SAInz MORENo

SUMARIO DEL NUM. 97 (enero-abril 1982)

\section{ESTUDIOS:}

- F. GarRido Falla: «Reflexiones sobre una reconstrucción de los límites formales del Derecho administrativo español».

- M. Bassols y J. M. Serrano: «El artículo 149 de la Constitución en relación con el artículo 150, 2: análisis de la delegación en materia de competencias estatales exclusivas».

- R. Echenique GoRdillo: "Los recursos en la Ley de expropiación forzosa».

- J. I. JIMÉNEz NiETo: «Origen del presupuesto por programas: una conmemoración».

- L. Ortega: «La inconstitucionalidad de la reforma de la Ley orgánica de referéndum».

- M. Alba Navarro: «Las facultades de iniciativa, propuesta e informe en materia legislativa del Consejo General del Poder Judicial».

\section{JURISPRUDENCIA:}

I. Comentario monográfico:

- F. LOPEZ-FoNT: «El término en el contrato administrativo de obra».

II. Notas:

Contenciosoadministrativo:

- A) En general (T. Font I Llovet y J. Tornos Mas).

- B) Personal.

\section{CRONICA ADMINISTRATIVA}

\section{BIBLIOGRAFIA}

\section{PRECIOS DE SUSCRIPCION ANUAL:}

España

Portugal, Iberoamérica y Filipinas ... ... .......

Otros países

$\begin{array}{lllllllllll} & \ldots & \ldots & \ldots & \ldots & \ldots & \ldots & \ldots & \ldots & \ldots & \ldots\end{array}$

Número suelto para España $\ldots \ldots \ldots \ldots \ldots \ldots$

Número suelto para extranjero

1.850 ptas.

$28 \$$

$29 \&$

800 ptas.

$11 \$$

\section{CENTRO DE ESTUDIOS CONSTITUCIONALES}

Pedidos: Plaza de la Marina Española, 9

MADRID-13 (España) 